\title{
Comparison of Lateral Internal Sphincterotomy with Topical Nitro- glycerine Treatment in Patients with Chronic Anal Fissure: A Prospective Randomised Study
}

\section{Fahri Yetisir ${ }^{1 *}$, A. Ebru Salman², Banu Yurekli ${ }^{3}$, Mustafa Aksoy ${ }^{4}$, Murat B.Yildirim ${ }^{5}$ and Mehmet Kilic ${ }^{5}$}

${ }^{1}$ Atatürk Etlik Research and Training Hospital, General Surgery Department, Turkey

${ }^{2}$ Ataturk Research and Training Hospital, Anaesthesiology and Reanimation Department, Turkey

${ }^{3}$ Bozyaka Research and Training Hospital, Endocrinology, Turkey

${ }^{4}$ Ataturk Research and Training Hospital, General Surgery Department, Turkey

${ }^{5}$ Yıldırım Beyazıt University, General Surgery Department, Turkey

\begin{abstract}
Aim: Lateral Internal Sphincteromy (LIS) is considered as gold standard in the treatment of chronic anal fissure. However, LIS has complications such as gas and stool incontinence. The aim of the present study was to compare the results of LIS and $0.4 \%$ topical nitroglicerin treatment in patients with chronic anal fissure.

Method: 150 patients with Chronic Anal Fissure were prospectively randomised into two Groups of 75 subjects in each. Group I underwent LIS and Group 2 was administered topical nitroglicerin. All patients were given high fibre diet and phsyllium diet before and after the treatment. After follow up period, two Groups were compared in terms of postoperative complications, recurrence rates, loss of work days and patient satisfaction.
\end{abstract}

Results: Two Groups were similar in terms of demographic data and anal fissures. Recurrence was seen in 4 patients in Group I and 8 patients in Group II. Gas incontinence under stress developed in 7 patients in Group I, in no patient Group II. Anal itching and soiling occurred in 8 patients in Group I, in no patient Group II. In Group II, headache occurred in 12 patients during treatment. Duration of time to return to work and normal activity was longer in Group I.

Conclusion: It is our suggestion that topical nitroglicerin is as effective as surgery in the treatment of chronic anal fissure with absence of incontinence.

Keywords: Anal Fissure; Glyceryltrinitrate; Sphincterotomy

\section{Introduction}

Anal Fissure (AF) is a common disease of anal canal, characterized by cracks or tears appearing on stratified squamous epithelium of anoderm. Anal fissure occurs especially in young healthy adults without any other medical problems [1]. Chronic AF are deep lesions lasting for more than 6-8 weeks and generally extending into the muscle fibres of Internal Anal Sphincter (IAS). It is characterized by persistent hypertonia and IAS spasm. IAS hyper tonicity and relative lack of blood supply in midline caused by it results in the development of an ischemic ulcer and refractory fissure [2-4]. The surrounding area of the fissure is raised due to inflammation and scarring. This inflammation may lead to the development of skin tags or a hypertrophic papilla in anal canal. Lateral Internal Sphincterotomy (LIS) treatment is considered as gold standard in the treatment of chronic anal fissure. However, LIS has complications such as gas and stool incontinence. Starting from 1990's, methods alternative to surgery have been developed. Among these, topical nitroglicerin and calcium channel blocker treatment and botulinum toxin injection can be considered. The aim of the present study was to compare the results of LIS and $0.4 \%$ topical nitroglicerin treatment in patients with chronic anal fissure and instituted psyllium treatment and high fibre diet.

\section{Material and Method}

After informed consent was obtained from patients and approval from ethics committee, 150 patients with chronic anal fissure refractory to 2 month medical treatment in our centre were included into the study. All patients were given high fibre diet (unprocessed wheat) and psyllium treatment in $4.5 \mathrm{gm}$ powder form twice a day (Nutraxın Psyllium Husk Fibre) with plenty of water 2 months before the treatment until to the end of the follow-up period. Sitting in hot water bath twice a day was recommended. Defecation training was given to all patients. The presence of hypertrophic anal papilla, linear mucosal tear extending to the internal sphincter fibres and of sentinal skin tag was recorded. Duration passing with symptoms of the patients was also recorded. The patients with inflammatory bowel disease, age below 16 years and above 70 years, those who are American Society of Anesthesiologists (ASA) 3 and 4 who have extra perennial disorders (grade 3,4 haemorrhoid, fistula, incontinence, carcinoma), patients with a history of perennial operation and patients with fissures located other than posterior site were excluded from the study (Figure 1). Patients were randomised into two Groups of 75 subjects in each. Patients in Group I underwent open LIS. After incision was made parallel to intersphincteric groove at hour three position, LIS was carried out in accordance with the length of the fissure under general or spinal anaesthesia in lithotomic position. Sphincterotomy was made along the length of fissure so that the rate of postoperative incontinence would not increase $[5,6] 0.4 \%$ topical nitroglycerine ( 15 gm lanoline +15 gm vaseline $+150 \mathrm{mg}$ nitroglycerine $1 \%$ ) treatment was administered to the patients in Group II for $8 \pm 2$ weeks $1.5 \mathrm{mg}$ two times a day. Patients were informed that topical nitroglycerine should be applied as much as half of a pea at each application. Diclofenac sodium 75

*Corresponding author: Fahri Yetisir, Ataturk Research and Training Hospital Department of General Surgery, Turkey, Tel: +90 53629748 88; E-mail: drfahriyetisir@hotmail.com

Received October 18, 2012; Accepted October 27, 2012; Published November 02, 2012

Citation: Yetisir F, Salman AE, Yurekli B, Aksoy M, Yildirim MB, et al. (2012 Comparison of Lateral Internal Sphincterotomy with Topical Nitro-glycerine Treatment in Patients with Chronic Anal Fissure: A Prospective Randomised Study. Surgery Curr Res 2:123. doi:10.4172/2161-1076.1000123

Copyright: $\odot 2012$ Yetisir F, et al. This is an open-access article distributed unde the terms of the Creative Commons Attribution License, which permits unrestricted use, distribution, and reproduction in any medium, provided the original author and source are credited. 
Citation: Yetisir F, Salman AE, Yurekli B, Aksoy M, Yildirim MB, et al. (2012) Comparison of Lateral Internal Sphincterotomy with Topical Nitroglycerine Treatment in Patients with Chronic Anal Fissure: A Prospective Randomised Study. Surgery Curr Res 2:123. doi:10.4172/2161 1076.1000123

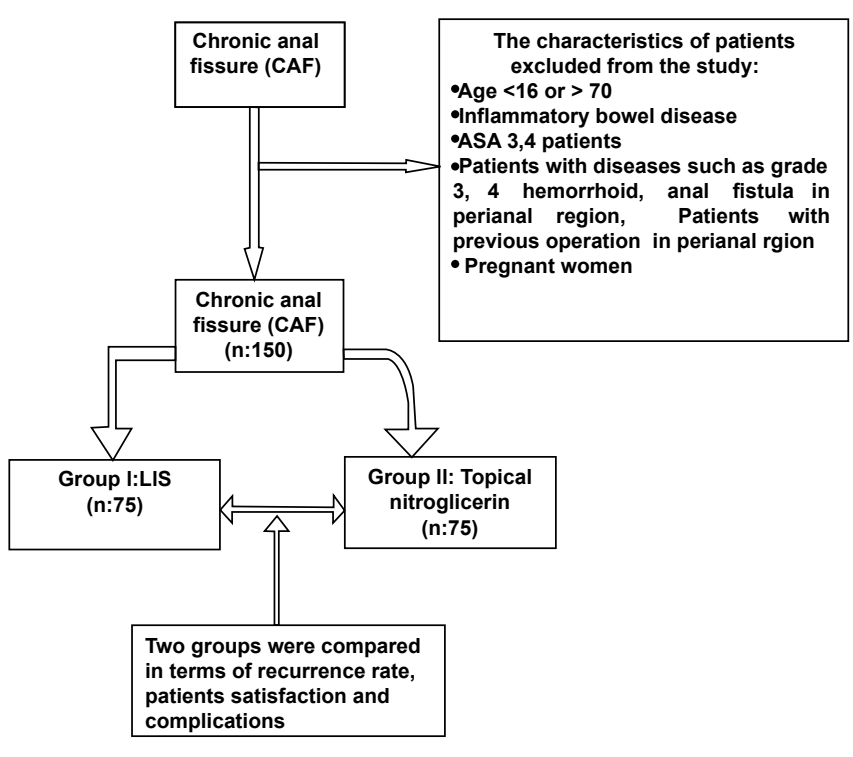

Figure 1: Study flow chart.

SR was prescribed to both Groups as oral analgesic and the patients were informed that they can use it twice a day in case of pain. VAS score during defecation was questioned in all patients at 2 weeks after treatment. They were called for control on average $16.1 \pm 3.4$ months later and VAS score was questioned. Perennial region of the patients was examined. The degree of improvement in fissures was controlled in all patients and wound site was controlled in those who underwent operation. The presence of bleeding, gas and stool incontinence, headache and soiling of underwear were recorded. Losses of work days for working patients were also recorded.

\section{Statistical Analysis}

\section{Primary statistics}

The characteristics of the patients were outlined with primary statistics. In the summary of numerical parameters, mean and standard deviation and in categorical variables number and percentage values were employed. $p$ value of 0.05 was considered as statistically significant. Statistical analysis was carried out with SPSS version 16.0 program.

\section{Secondary comparisons}

In comparisons, to determine the distribution of all variable Groups Kolmogorov-Smirnov tests was used and in normally distributed and parametric variables, for not normally distributed variables nonparametric statistical methods were used. As parametric test, Student's $t$ test (independent sample $t$ test) and as non-parametric test, MannWhitney $\mathrm{U}$ Test was used. In the comparison of categorical variables cross-table statistics were used (Chi-square and Fisher tests).

\section{Results}

There was no difference between demographic data in two Groups (Table 1). The features of chronic anal fissures were similar between two Groups (Table 2). In Group I, gas incontinence under stress was seen in 7 (9.4\%) patients and in any of the patients in Group II. $(\mathrm{p}=0.014)$. Anal pruritis and soiling occurred in $8(10.6 \%)$ patients in Group I and in any of the patients in Group II ( $\mathrm{p}=0.007)$, (Table 3). There was no difference in recurrence rate between two Groups (Table
4). In Group I, VAS score during defecation was $8.49 \pm 0.8$ before treatment while it was $1.1 \pm 1.8,2$ weeks after treatment and $0.9 \pm 1.5$ at the end of the follow up period. In Group II VAS score was $8.44 \pm 1.3$ before treatment, while it was $1.52 \pm 1.0$ two weeks after treatment and $1.2 \pm 1.3$ at the end of the follow-up period. There was no difference in VAS scores between two Groups at all measurement times. In Group II, headache occurred in 12 patients $(16.4 \%)$ during treatment, whilst it occurred in no patient in Group I $(\mathrm{p}<0,001)$. But the mean VAS score of these patients was $3.4 \pm 0.9$. In Group I, the mean duration of return to daily activity was $4.77 \pm 1.75$ days, while in Group II, it was $0.04 \pm$ 0.2 days $(\mathrm{p}<0.001)$. In Group I, mean of loss of work days was $17.5 \pm 5.9$ days, while it was $1.9 \pm 1.8$ days $(\mathrm{p}<0,001)$ in Group II. Post-treatment results of patients were summarized in (Tables 3 and 4 ).

\section{Discussion}

In a study by Schouten et al. [7] of 24 patients with chronic anal fissure who underwent LIS, decrease in anal pressure was observed in $35 \%$ of patients while a constant increase was observed in blood circulation in that region in $65 \%$ of patients. Traumatic laceration of anoderm is the major triggering factor [7]. In patients with previous increase in internal sphincter tonus, the rate of recovery is slow in traumatic lesions of anoderm. Impaired perfusion of anoderm especially in posterior midline results in ischemic ulceration [7]. It has been reported that in elderly and postpartum patients anal fissures are associated with normal and even hypotonic sphincters [8,9]. In the

\begin{tabular}{|l|l|l|l|}
\hline & Group I: $(\mathbf{n}=\mathbf{7 5})$ & Group II: $(\mathbf{n}=\mathbf{7 5})$ & p value \\
\hline Age & $40.5 \pm 14.3$ & $36.4 \pm 11.4$ & 0.150 \\
\hline Female /Male & $30 / 45$ & $24 / 51$ & 0.307 \\
\hline ASA I/II & $58 / 17$ & $57 / 18$ & 0.847 \\
\hline
\end{tabular}

Table 1: Demographic characteristics.

\begin{tabular}{|l|l|l|l|}
\hline & Group I & Group II & p value \\
\hline Rectal Bleeding & $65(86.7 \%)$ & $68(90.7 \%)$ & 0.440 \\
\hline Pain during defecation & $75(100 \%)$ & $75(100 \%)$ & 1.000 \\
\hline Skin tag & $54(72 \%)$ & $51(68 \%)$ & 0.593 \\
\hline Anal papilla & $42(56 \%)$ & $49(65.3 \%)$ & 0.242 \\
\hline Deep fissure & $44(58.7 \%)$ & $50(66.7 \%)$ & 0.311 \\
\hline Mean duration of complaints (year) & $4.7 \pm 1.9$ & $4.3 \pm 2.8$ & 0.337 \\
\hline
\end{tabular}

Table 2: The number and percentage of patient characteristics of chronic ana fissures in groups.

\begin{tabular}{|l|l|l|l|}
\hline & Group I & Group II & p value \\
\hline Spontaneous Gas incontinence & $3(4 \%)$ & 0 & 0.248 \\
\hline Gas incontinence under stress & $7(9.4 \%)$ & 0 & 0.014 \\
\hline Spontaneous stool incontinence & $1(1.3 \%)$ & 0 & 1.000 \\
\hline Stool incontinence under stress & $3(4 \%)$ & 0 & 0.248 \\
\hline Anal wetting or soiling & $8(10.6 \%)$ & 0 & 0.007 \\
\hline Patients with anal abscess or fistula & $1(1.3 \%)$ & 0 & 1.000 \\
\hline $\begin{array}{l}\text { Temporary headache during treatment } \\
\text { and VAS score }\end{array}$ & 0 & $12(16.4 \%)$ & $<0.001$ \\
\hline
\end{tabular}

Table 3: Post treatment results of patients.

\begin{tabular}{|l|l|l|l|}
\hline & Group I & Group II & p value \\
\hline Patients completing treatment (\%) & $74(98.7 \%)$ & $73(97.3 \%)$ & \\
\hline $\begin{array}{l}\text { Patients with recurring complaints } \\
\text { (\%) }\end{array}$ & $4(5.4 \%)$ & $8(10.9 \%)$ & 0.219 \\
\hline $\begin{array}{l}\text { Time to return to normal activities } \\
\text { post-treatment (day) }\end{array}$ & $4.77 \pm 1.75$ & $0.04 \pm 0.2$ & $\begin{array}{l}<0.001 \text { (Mann- } \\
\text { Whitney u test) }\end{array}$ \\
\hline Post-treatment. loss of work days & $\begin{array}{l}\text { (n:48) } 17.5 \\
\pm 5.9\end{array}$ & $\begin{array}{l}\text { (n:44) } 1.9 \\
\pm 1.8\end{array}$ & $\begin{array}{l}<0.001 \text { (Mann- } \\
\text { Whitney u test) }\end{array}$ \\
\hline
\end{tabular}

Table 4: Post treatment results of patients. 
Citation: Yetisir F, Salman AE, Yurekli B, Aksoy M, Yildirim MB, et al. (2012) Comparison of Lateral Internal Sphincterotomy with Topical Nitroglycerine Treatment in Patients with Chronic Anal Fissure: A Prospective Randomised Study. Surgery Curr Res 2:123. doi:10.4172/21611076.1000123

treatment of Chronic Anal Fissure, LIS has a high success rate as high as $95 \%$. However, the rate of incontinence after LIS varies between $0 \%$ $50 \%$ [10]. This rate changes depending on operation technique and type and duration of postoperative follow up [11]. Mentes et al. [12] carried out a prospective randomised study comparing Sphincterotomy Groups made either until fissure apex or dentate line and found that the rate of incontinence was higher in the Group where the incision was made until dentate line [12]. In a prospective randomised controlled study carried out by Valizedah et al. [13] botilinum toxin injection and LIS were compared in the treatment of chronic anal fissure. After a follow up period of six months, it was found that the rate of recurrence was significantly higher in botilinum toxin injection Group. However, the rate of anal incontinence was higher in LIS Group, although the difference was not statistically significant. Sinha and Kaiser [14] described an algorithm in the treatment of Chronic Anal Fissure in order to decrease the risk of anal incontinence in 209 patients. All patients were offered all steps of the algorithm glyceryltrinitrate (GTN)Botox-surgery, unless symptoms or patient preference demanded more aggressive treatment and only $26.3 \%$ of the patients required surgery. Among 141 patients using GTN, symptoms continued in 58 (41.1\%) patients after a mean follow up period of 16 months [14]. Our findings are in accordance with this study. We also proposed that all patients with chronic anal fissure should be treated with topical nitroglycerine ointment as a first line therapy. The tonus of IAS is influenced by neurohumoral substances and inhibitor neurotransmitters. Alpha and beta agonists and vasointestinal polypeptide and nitric oxide are among these $[15,16]$. There is compelling evidence supporting the important role played by nitric oxide in the relaxation of IAS $[17,18,19]$. It was demonstrated in a study that in patients with anal fissure, Nitric Oxide Synthase (NOS) activity decreased in IAS [20-22]. This may account for the increase in anal pressure in patients with anal fissure and its returning to normal when it is treated by non-surgical methods. Nitric oxide is a free radical with a half-life of a few seconds. Nitric oxide activates soluble guanilate-cyclase and increases the level of c-GMP (guanosine 3'-5'cyclic monophosphate), which in turn causes relaxation of smooth muscles [23]. Components of Chronic Anal Fissure influence the success rates of various medical treatments. In a study by Arslan et al. [24] in patients with Chronic Anal Fissure receiving isosorbide dinitrate treatment, success rates were found to be lower in patients with persistant fissure, sentinel skin tag and hypertrophic anal papilla than those in patients with only one or two of these components. Topical nitroglicerin treatment has side effects such as moderately severe transient headache and feeling of burning in anal region. Its rate may be as high as $25 \%[25,26]$. In the present study, its rate was found to be $16.4 \%$. However, there is no evidence of the development of anal incontinence during treatment. The rate of recurrence after topical nitroglicerin treatment is reported to be high in various studies, while in the present study, it was found to be $10.9 \%$. Lower rates may be due to the support of treatment by psyllium, which is an intestinal regulator [27]. Psyllium may have exerted its effect by preventing the formation of hard stool causing mechanical trauma responsible for the development of chronic anal fissure and diarrheal attacks. Recent studies have emphasized that topical nitroglicerin at $0.04 \%$ concentration $2 \times 1.5 \mathrm{mg}$ is the most efficient dose in treatment of chronic anal fissure [28,29]. In a study carried out by Ergun et al. [30] on 568 pharmacists, it was shown that only $24(\% 4)$ of the pharmacists prepared topical nitroglicerin prescription and \%0.4 nitroglicerin content was not found exactly at this ratio in preparations. Lack of a standard product containing topical nitroglicerin and the preparation of this cream magisterially in many countries such as Turkey are the factors influencing the success of treatment. In addition to these, a large majority of pharmacists do not know how to prepare topical nitroglycerin. Finally due to inadequate patient compliance to treatment and the difference in the duration of follow up of patients are the other factors affecting the success of the topical nitroglycerin treatment. Although long terms results with larger patient series are required, it is our conclusion that topical nitroglicerin treatment, which causes no incontinence and decreases the duration of returning to normal daily activities and work for patients may be as effective as surgical treatment in the treatment of Chronic Anal Fissure, provided that it is used regularly together with conservative treatment.

\section{References}

1. Qureshi U, Khan JS, Malik AS, Khan MM (2008) Surgical versus nonsurgical treatment of chronic anal fissure: Our local experience. Ann Pak Inst Med Sci 4: 193-197.

2. Schouten WR, Briel JW, Aurwerda JJ, De Graaf EJ (1996) Ischaemic nature of anal fissure. Br J Surg 83: 63-65.

3. Utzig MJ, Kroesen AJ, Buhr HJ (2003) Concepts in pathogenesis and treatment of chronic anal fissure: a review of the literature. J Gastroenterol 98: 968-974.

4. Lund JN, Scholefield JH (1996) Aetiology and treatment of anal fissure. $\mathrm{Br}$ Surg 83: 1335-1344.

5. Collins EE, Lund JN (2007) A revive of chronic anal fissure management. Tech Coloproctol 11: 209-223.

6. Littlejohn DR, Newstead GL (1997) Tailored lateral internal Sphincterotomy for anal fissure. Dis Colon Rectum 40: 1439-1442.

7. Schouten WR, Briel JW, Auwerda JJA, De Grraaf EJR (1996) Ischaemic nature of anal fissure. Br J Surg 83: 63-65.

8. Corby H, Donnelly VS, O'Herlihy C, O'Connell PR (1997) Anal canal pressures are low in women with postpartum anal fissure. Br J Surg 84: 86-88.

9. Bove A, Balzano A, Perrotti P, Antropoli C, Lombardi G, et al. (2004) Different anal pressure profiles in patients with anal fissure. Tech Coloproctol 8: 151156.

10. Menteş BB, Irkorucu O, Akın M, Leventoğlu S, Tatıcıoğlu E (2003) Comparison of botulinum toxin injection and lateral sphincterotomy fort he the treatment of chronic anal fissure. Dis Colon Rectum 46: 232-237.

11. Zbar AP, Aslam M, Allgar V (2000) Fecal incontinence after internal sphincterotomy for anal fissure. Tech Coloproctol 4: 255-288.

12. Menteş BB, Ege B, Leventoğlu S, Oğuz M, Karadağ A (2005) Extent of lateral internal sphincterotomy: up to dentate line or up to the fissure apex? Dis Colon Rectum 48: 365-370.

13. Valizedah N, Jalaly NY, Hassanzadeh M, Kamani F, Dadvar Z, et al. (2012) Botulinum toxin injection versus lateral internal sphincterotomy for the treatment of chronic anal fissure: randomized prospective controlled trial. Langenbecks Arch Surg.

14. Sinha R, Kaiser AM (2012) Efficacy of management algorithm for reducing need for Sphincterotomy in chronic anal fissures. Colorectal Dis 14: 760-764.

15. Rattan S (2005) The internal anal sphincter: regulation of smooth muscle tone and relaxation. Neurogastroenterol Motil 17: 50-59.

16. O'Kelly TJ, Davies JR, Brading AF, Mortensen NJ (1994) Distribution of nitric oxide synthase containing neurons in the rectal myenteric plexus and anal canal, Morphologic evidence that nitric oxide mediates the rectoanal inhibitory reflux. Dis Colon Rectum 37: 350-357.

17. Lund JN, Scholefield JH (1996) Aetiology and treatment of anal fissure. Brit Surg 83: 1335-1344.

18. Rattan S, Chakder S (1992) Role of nitric oxide as a mediator of internal anal sphincter relaxation. Am J Phsiol 262: G107-G112

19. O'Kelly TJ (1996) Nerves that say NO: a new perspective on the human rectoanal inhibitory reflex. Ann R Coll Surg Engl 78: 31-38.

20. Fung H-L (1993) Clinical pharmacology of organic nitrates. Am J Cardiol 72 9-13.

21. Rattan S, Chakder S (1992) Role of nitric oxide as a mediator of internal ana sphincter relaxation. Am J Physiol 262: 107-112. 
Citation: Yetisir F, Salman AE, Yurekli B, Aksoy M, Yildirim MB, et al. (2012) Comparison of Lateral Internal Sphincterotomy with Topical Nitroglycerine Treatment in Patients with Chronic Anal Fissure: A Prospective Randomised Study. Surgery Curr Res 2:123. doi:10.4172/2161 1076.1000123

22. Lund JN (2006) Nitric oxide deficiency in the internal anal sphincter of patients with chronic anal fissure. Int $\mathrm{J}$ Colorectal Dis 21: 673-675.

23. Davies MG, Fulton GJ, Hagen PO (1995) Clinical biology of nitric oxide. Br J Surg 82: 1598-1610.

24. Arslan K, Erenoğlu B, Doğru O, Kökçam S, Turan E, et al. (2012) Effect of chronic anal fissure components on isosorbide dinitrate treatment. World $\mathrm{J}$ Surg 36: 2225-2229.

25. De Nardi P, Ortolano E, Radaelli G, Staudacher C ( 2006) Comparison of glyceryl trinitrate and botilunum toxin -a for the treatment of chronic anal fissure, long term results. Dis Colon Rectum 49: 427-432.

26. Fenton C, Wellington K, Easthope SE (2006) $0.4 \%$ nitroglycerin ointment: in the treatment of chronic anal fissure pain. Dugs 66: 343-349.
27. Van der Hagen SJ, Soeters PB, Baeten CG, Van Gemert WG (2011) Consevative treatment of patients with faecal soiling. Tech Coloproctol 15 291-295.

28. Scholefield JH, Bock JU, Marla B, Richter HJ, Athanasiadis S, et al. (2003) A dose finding study with $0.1 \%, 0.2 \%$ and $0.4 \%$ glyceryl trinitrate ointment in patients with chronic anal fissures. Gut 52: 264-269.

29. Bailey HR, Beck DE, Billingham RP, Binderow SR, Gottesman L, et al. (2002) A study to determine the nitroglycerin ointment dose and dosing interval that best promote the healing of chronic anal fissures. Dis Colon Rectum 45: 1192-1199.

30. Ergun H, Berk B, Uludag M, Diler, Erol DD, et al. (2010) was prepared in pharmacies in Turkey (magistral) nitroglycerin ointments evaluated in terms of content and presentation features. Marmara Pharmaceutical Journal 14: 130 135. 